\title{
SIMULATION ANALYSIS OF THE WEEKEND EFFECT'S PROBLEM
}

\author{
Boris Frenkel, Dmitry Alberg, Ilia Frenkel \\ Industrial Engineering and Management Department, \\ Negev Academic College of Engineering - NACE, Beer Sheva, 84100, Israel
}

Received 10 January 2004; accepted 27 February 2004

\begin{abstract}
The proposed paper uses the simulation approach to the analysis of the model, which explains the essence of the 'Weekend Effect' existing on the world's stock exchanges. This effect contains the difference of the daily working ratio between Saturday and Monday. The stock market is considered as the Queuing System functioning according to the Matchmaker concept.
\end{abstract}

Keywords: weekend effect, simulation, queue, matchmaker, non-homogeneity, non-stationarity.

\section{Introduction}

For a long time at the world stock markets, the socalled 'Weekend effect' (WE) or Monday effect has existed. Its essence lies in the difference of the daily average working ratio between Saturday and Monday. According to the theory of finance, the math waiting criteria on Saturday have to be equal to those on Monday. But, in reality, a stable difference is observed. Nowadays, there is no vivid model that explains the Weekend Effect, which has been given the status of anomaly.

The term 'Weekend Effect' was registered in 1973 for the first time by Cross [2] and formally came into existence from 1980 after publishing the French's paper [5], that described the effect based on the S\&P500 data covering the years from 1953 up to 1977. The same effect was named in 1984 The Monday Effect by Rogasky [10].

There exist 2 types of the Weekend Effect and, particularly negative, when the Monday ratio is lower than Saturday's and positive when it is higher. This effect is observed on the whole world stock markets, not depending on the work schedule [7] or kind of valuable shares (options, shares, indexes, interest bearings, etc.) [5], [10].

Many efforts have been made to explain the effect. In 1981 Gibbons and Hess [6] proposed their misspecification; in 1982 Lakonishok and Levi [8] supposed that the explanation to this effect might be the difference in waiting time between the buycustomers and sale ones. In 1998, Fortune [4] proposed the Jump Diffusion explanation and in 2001, Chan and Singa [1] published their speculative Short Sales. In recent years, many efforts have been made to employ different types of econometric models, but not successfully. The most striking disadvantage of all these efforts was the low value of $R^{2}$.

The proposed paper introduces the model which explains the Weekend Effect in terms of random processes and a queuing theory, showing the mechanism of its appearing and uniting together all the above-mentioned explanations. 


\section{Model}

Let us consider a stock market, where one share exists for the buy-and-sale process and there are many participants taking part in the process. This system may be assumed as the mass service queuing system with two arriving flows: demand and offer. There are 3 parameters for each flow: customer time, proposed or required quantity and price. Each of these parameters is considered a random variable. The arriving (entering) flows are supposed to be random, Non-homogeneous and non-stationary. All the customers enter the stock market, which is considered here as a server, functioning according to the Matchmaker concept [3, 9].

Each entering buy-customer is matched with the corresponding sale-customer. If the buy-price is maximally close to the demand-price, the transaction takes place in terms of minimum from two proposed quantities (buy and demand). If the transaction is not fulfilled completely, the server starts serving the next one in the queue. When there is no offer suitable for the demand, the buy-transaction occurs in the queue for buy-transactions. The queue is organized according to prices in descending order, primarily, and to the time of entering the queue as a minor factor. Saletransactions are being served in the same manner.

Sales take place constantly during the work week (in this case any finite time period may be taken). On the Weekend, no sales take place. The unserved transactions are left in the queue for the next week. Full served transactions aren't returned back and there is no such thing as complex compound requisition (FOK). All the above-mentioned limitations may be changed without any quality change of the results $[11,12]$.

Claim. The Weekend Effect results naturally from non-stationarity and non-homogenity of the entering processes.

To prove the statement, let us use the simulation approach. The program-simulator is developed in Visual Basic, employing Excel as a table editor. Fig 1 shows the block-diagram of the simulator.

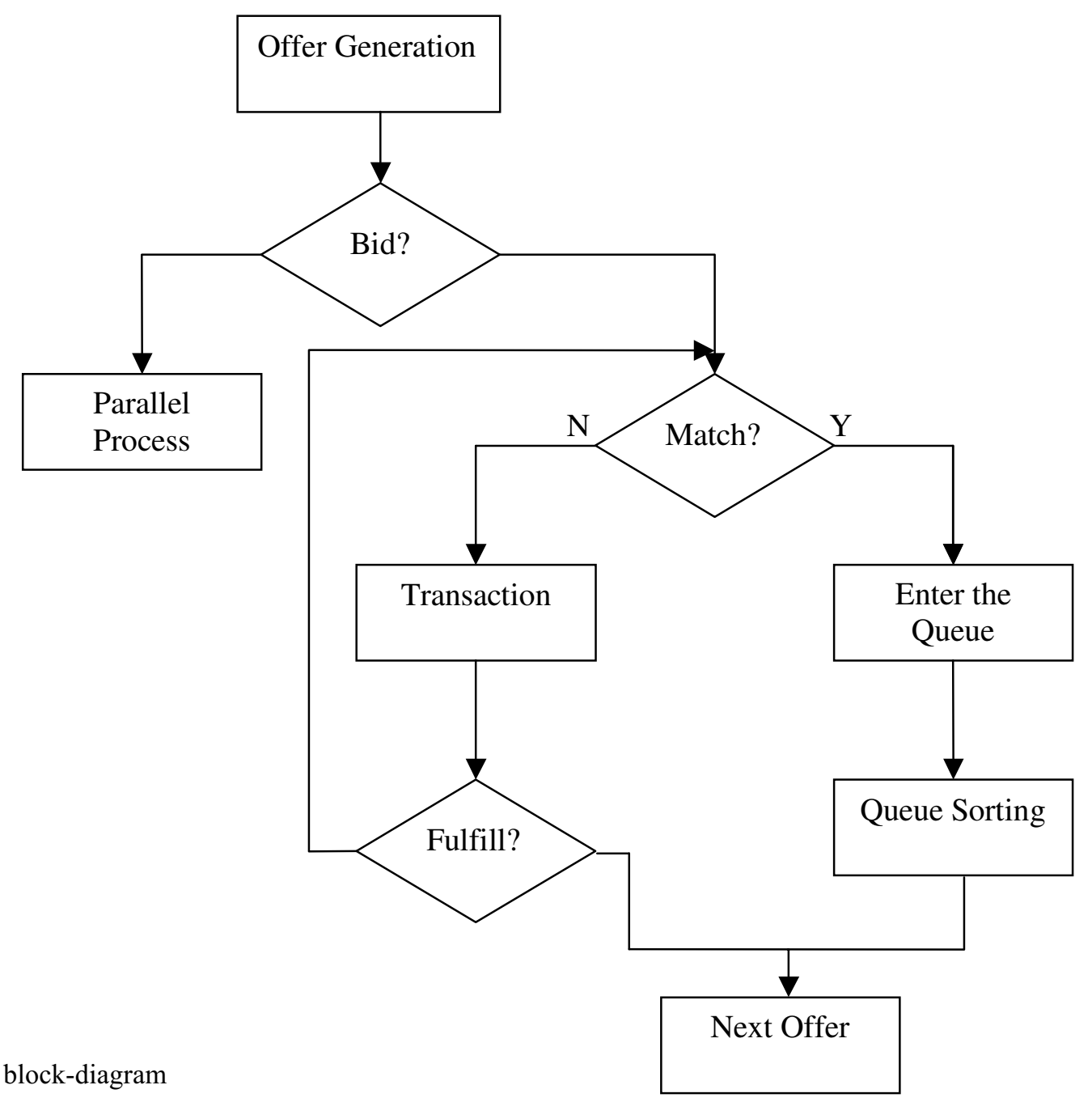

Fig 1. Simulator block-diagram 
These are the following assumptions used in the program:

1) The price of each transaction is written down.

2) The working week lasts for 100 time units.

3) To neutralize the influence of autoregression, seasoning and trend, the sale week starts with the price of 100 units.

4) At the end of the week, the final transaction price is registered as well as the difference between the initial and final prices (WE).

5) The simulation is produced for a 100 week period.

Let us define random variable $X$ as the difference in price between the beginning and the end of the week, and check the null hypothesis i.e. $\mu_{x}=0$ using the Student Test with $\alpha=0.05$.

\section{Simulation Results}

Let us introduce 3 types of simulation runs: customers' arrivals are homogeneous and stationary, customers' arrivals are non-homogeneous and non-stationary in terms of offered quantity and customers' arrivals are non-homogeneous and non-stationary in terms of offered price.

\subsection{The first type of simulation: customers' arrivals are homogeneous and stationary}

The entering processes are generated according to the following rules:

- Intervals between customer arrivals are distributed exponentially.

- The offered quantity of customers according to the average arrival rate has a Poisson distribution with $\lambda$. Only an integer number of shares is allowed, while the offer of zero amount of shares is prohibited.

- The offered price is normally distributed with the mean value, equal to the price of the previous transaction (at the beginning of the week the sum is 100 price points) and standard deviation is equal 10 . To simplify the process, continuous values are allowed. In case the price decreases down to zero, the trades are over.

The differences between the opening and closing prices of 100 weeks of simulation are represented in Fig 2. We gain the following results:

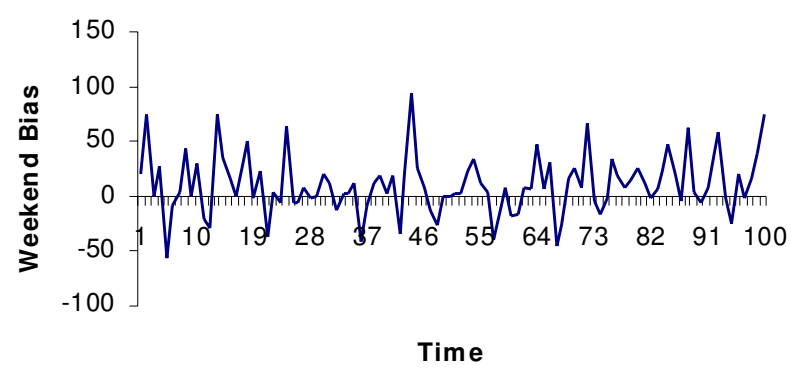

Fig 2. The first type simulation results: customers' arrivals are homogeneous and stationary

$$
\begin{aligned}
\bar{x} & =-1.09076, \\
s_{d} & =24.73328, \\
t_{\text {stat }} & =-0.44101 .
\end{aligned}
$$

The null hypothesis is not rejected; there is no possibility to prove the weekend effect existence, when the complete homogeneity and stationarity of entering processes take place.

\subsection{The second type of simulation: customers' arrivals are non-homogeneous and non-stationary in terms of offered quantity}

Let us consider a variant more close to reality, when the market components are changing during the week. Assume that to simplify the description that sale customers at the end of the trade week are being delivered in a more intensive tempo and in smaller quantities than buy customers. Comparing this process to the analogical one, but taking place at the week's start.

Then the generation of the processes is produced in accordance with the following rules:

- Buy-customers are delivered exponentially with $\lambda=1$ during the hole week.

- Sale-customers are delivered exponentially with $\lambda=1$ at the beginning of the week and with $\lambda=2$ at the end of the week (linear growth).

- The offered purchase-quantity distributed Poisson with $\lambda=0.01$ during the whole trade week.

- The offered sale-quantity has the Poisson distribution from $\lambda=0.01$ at the beginning of the week and from $\lambda=0.02$ at the end of the week (linear growth).

- The mechanism of price generation is identical to the previous variant (see the first type of simulation).

The differences between the opening and closing prices of 100 weeks of simulation are represented in the Fig 3. 


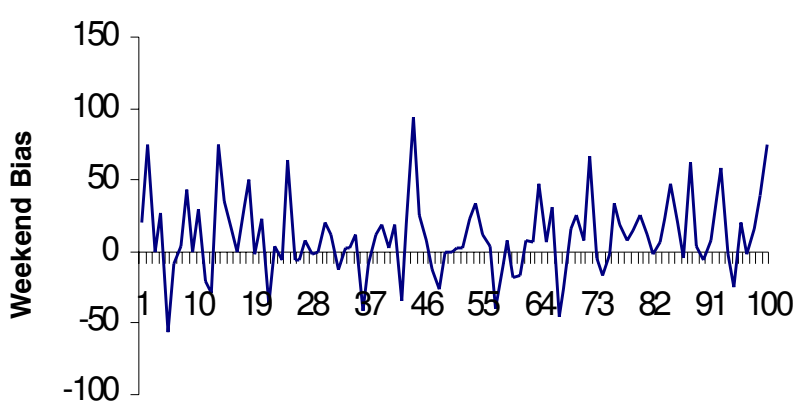

Time

Fig 3. The first type of simulation results: customers' arrivals are non-homogeneous and non-stationary in terms of offered quantity

We gain the following results:

$$
\begin{aligned}
& \bar{x}=10.58209, \\
& s_{d}=27.55256, \\
& t_{\text {stat }}=3.84069 .
\end{aligned}
$$

Considering the gained results, it becomes vivid, that now we can reject the null hypothesis; nonhomogeneity and non-stationarity of customers in terms of offered quantity from the weekend effect.

\subsection{The third type of simulation: customers' arrivals are non-homogeneous and non-stationary in terms of offered price}

The last proposed variant investigates the weekend effect as the result of price generation's non-homogeneity. Assume that the amount of purchase customers is changes in the non-linear manner during the trade week and it is according to the following law:

- Intervals between customers' arrivals as well as offered quantity are distributed exponentially on analogy with the first type of simulation.

- The offered price is distributed normally with mean value equal to the previous transaction price

- The standard deviation of sale-customer price is equal to the second root of the mean value, multiplied by the ratio of the minimal offered purchase price in queue.

Fig 4 represents the differences between the opening and closing prices of 100 weeks of simulation:

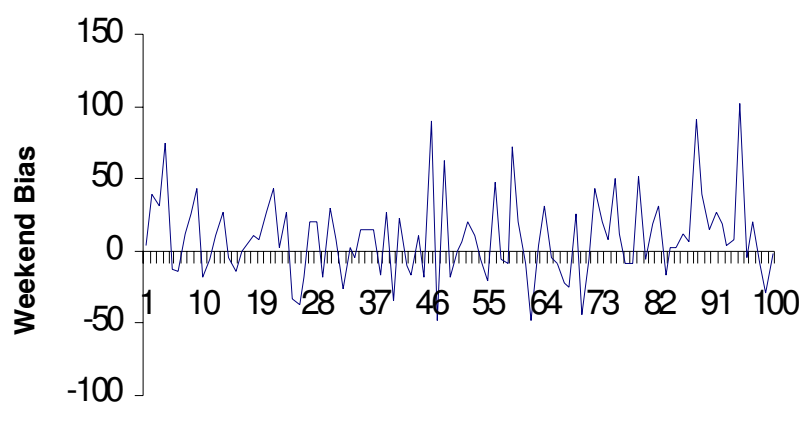

Time

Fig 4. The third type simulation results: customers' arrivals are non-homogeneous and non-stationary in terms of offered price

The following results have been gained:

$$
\begin{aligned}
& \bar{x}=8.8068, \\
& s_{d}=28.8239, \\
& t_{\text {stat }}=3.0553 .
\end{aligned}
$$

It becomes clear, considering the gained results, that the null hypothesis should be rejected. So we can vividly state, that it is non-homogeneity and nonstationarity that lead to the Weekend Effect.

\section{Conclusion}

To infer the results of the research, the following fact may come as a final conclusion: non-homogeneity and non-stationarity lead to the Weekend Effect.

While researching real stock exchange processes, it becomes vivid that the non-homogeneity and nonstationarity in terms of quantity as well as in terms of price takes place. The Weekend Effect, observed in the world stock exchanges comes as a result of nonhomogeneity and non-stationarity.

\section{References}

1. Chen, H.; Singal, V. Role of Speculative Short Sales In Price Formation: Case of The Weekend Effect. Virginia Tech, Working Paper, No 12, 2001.

2. Cross, F. The Behavior of Stock Prices on Fridays and Mondays. Financial Analysts Journal, Nov/Dec, 1973, p 67-69.

3. Flannery, M. J.; Protopapadakis, A. A. From T-Bills to Common Stocks: Investigating The Generality of IntraWeek Return seasonality. Journal of Finance, Vol 33, 1988, p 431-450.

4. Fortune. P. Weekend Can Be Rough: Revisiting The 
Weekend Effect in Stock Prices. Federal Reserve Bank of Boston, Working Paper, 1998, No 98-6.

5. French, K. R. Stock Returns and the Weekend Effect. Journal of Financial Economics, Vol 8, 1980, p 55-70.

6. Gibbons, M.; Hess, P. Day of The Week Effects and Asset Returns. Journal of Business, Vol 54, 1981, p 579596.

7. Jaffe, J.; Westerfield, R. The Weekend Effect in Common Stock Returns: The International Evidence. The Journal of Finance, Vol XL, No 2, 1985, p 40-65.

8. Lakonishok, J.; Levi, M. Weekend Effect and Stock Returns. Journal of Finance, Vol 37, 1982, p 883-889.
9. Lakonishok, J.; Maberly, E. The Weekend Effect: Trading Patterns of Individual and Institutional Investors. Journal of Finance, Vol 40, 1990, p 231-243.

10. Rogaski, R. New Findings Regarding Day of The Week Returns Over Trading and Non-Trading Periods. Journal of Finance, Vol 39, 1984, p 1603-1614.

11. Schwert, G. W. Anomalies and Market Efficiency. The Bradley Policy Researsh Center, Financial Research and Policy Working Paper, No FR 02-13, 2002.

12. Wang, K.; Li, Y.; Erickson, J. A New Look at The Monday Effect. The Journal of Finance, Vol LII, No 5, 1997, p 2171-2186. 